\title{
OPEN Eltrombopag for the treatment of refractory thrombocytopenia associated with connective tissue disease
}

\author{
Juan Wang, Min Dai, Qiong Fu \& Sheng Chen $\bowtie$
}

To assess the efficacy and safety of eltrombopag in connective tissue disease (CTD)-immune thrombocytopenia (ITP), we conducted this single-center retrospective observational study, including patients with refractory CTD-ITP who were treated with eltrombopag between January 2018 and August 2019. The characteristics of patients at baseline, and the efficacy and safety of the drug were analyzed. The predictors for a response were analyzed using a univariate analysis such as Chi-square or nonparametric test and a multiple correspondence analysis (MCA) method. A total of 15 patients with refractory CTD-ITP were included in the study. Their median age at the time of inclusion was 40.6 years. The median platelet count at initiation of eltrombopag was $11.53 \times 10^{9} / \mathrm{L}$. The median remission time was 3.42 weeks. The complete remission (CR) and overall response rate decreased with time. The factors that associated with response to eltrombopag in patients with CTD-ITP were protopathy, WBC counts, levels of hemoglobin, and characteristics of bone marrow findings in univariate analysis. In addition, MCA indicated that a poor response to eltrombopag in patients with refractory CTD-ITP was closely associated with a protopathy with SS, medium to severe degree of anemia, leukopenia, and bone marrow aspiration showing aplastic anemia, an absence of megakaryocytes or macrophage activation syndrome (MAS). In conclusion, eltrombopag was effective and well-tolerated in patients with CTD-associated thrombocytopenia. Some factors should be considered in the use of eltrombopag, including the protopathy, blood test, and bone marrow histology.

Thrombocytopenia is frequent in patients with connective tissue disease (CTD). Immune thrombocytopenia (ITP) may be a primary condition or it can be associated with other disorders, such as CTD. The systemic lupus erythematosus (SLE)-associated thrombocytopenia occurs in approximately $30 \%$ of cases $^{1}$. The primary goal of therapy for patients with chronic thrombocytopenia is to prevent severe bleeding by increasing platelets to $30 \times 10^{9} / \mathrm{L}$ to $50 \times 10^{9} / \mathrm{L}$ with few treatment-associated toxic effects ${ }^{2}$. At present, corticosteroids are used as the first-line therapy for CTD-related thrombocytopenia and second-line treatments, including immunosuppressive drugs, thrombopoietin (TPO), intravenous immunoglobulin (IVIG), splenectomy, and rituximab. Yet, not all patients respond well to this type of therapy.

Eltrombopag is an oral, small molecule, non-peptide thrombopoietin-receptor agonist that interacts with the transmembrane domain of the thrombopoietin receptor ${ }^{2}$. It promotes the proliferation and differentiation of megakaryocytes in bone marrow, resulting in a dose-dependent increase in normally functioning platelets ${ }^{2}$. Eltrombopag was approved by the FDA in 2008 for the treatment of ITP. Its efficacy and safety have been confirmed by many clinical and real-world trails in the course of the last ten years. However, so far, no clinical trials have been performed to evaluate the efficacy or safety of eltrombopag in patients with secondary ITP related to CTD. Few case reports have shown promising outcomes in SLE patients ${ }^{3-5}$. It showed that TPO mimetics are safe and good options for SLE-associated thrombocytopenia refractory to conventional immunosuppressive agents, and do not contribute to increased disease activity ${ }^{3-5}$. However, there is limited data on other CTD diseases except for SLE. Overall, more data are needed to confirm whether patients with CTD benefit from eltrombopag, taking into consideration the risk of severe adverse events, such as worsening of the underlying autoimmune dysregulation or thrombosis. 
Herein, we presented 15 CTD-related thrombocytopenia cases treated with eltrombopag in Renji Hospital, Shanghai Jiao Tong University, between January 2018 and August 2019.

\section{Materials and methods}

A total of 15 hospitalized patients with thrombocytopenia associated to CTD, including 9 patients with SLE, 3 patients with Sjögren's syndrome (SS), and 3 other patients diagnosed with undifferentiated connective tissue disease (UCTD) in the Renji hospital, Shanghai between January 2018 and August 2019 were enrolled in the study. We confirmed that informed consent was obtained from all subjects or, if subjects are under 18, from a parent guardian. All included patients showed a poor or no response to prior high-dose steroids and immunosuppressant, such as cyclosporine A, azathioprine, and rituximab, as defining refractory thrombocytopenia associated with CTD. Inclusion criteria were: (a) subjects who fulfilled the Systemic Lupus International Collaborating Clinics Criteria (2012) for SLE ${ }^{6}$, American College Rheumatology (ACR), and European League Against Rheumatism criteria (EULAR) (2016) for SS ${ }^{7}$ or diagnosed with UCTD; (b) the baseline platelet counts $\leq 30 \times 10^{9} / \mathrm{L}$. Patients with arterial thrombosis, a history of venous thrombosis necessitating anticoagulation therapy, splenectomy within 12 weeks before the first screening visit, and with active malignancy were excluded from the study.

Response criteria for treatment were as follows: (a) complete remission (CR), platelet count $\geq 100 \times 10^{9} / \mathrm{L}$ measured on 2 occasions (at least 7 days apart), and the absence of bleeding; (b) partial response(PR), platelet count $\geq 50 \times 10^{9} / \mathrm{L}$ measured on 2 occasions (at least 7 days apart), and the absence of bleeding ${ }^{8}$; (c) no response, a platelet count $<50 \times 10^{9} / \mathrm{L}$ or a less than twofold increase in platelet count from baseline or the presence of bleeding ${ }^{2}$. Patient characteristics and other treatments used for thrombocytopenia and their dose were also noted. The baseline platelet counts, platelet counts change curves, time to response (TTR), duration of treatment, the $\mathrm{CR}$ and $\mathrm{PR}$ rate during treatment, and adverse effects of eltrombopag were also analyzed. The predictors for a response were analyzed using a univariate analysis such as Chi-square or nonparametric test (Table 3), including age, gender, protopathy, platelet reduction time, prior therapy, anemia, white blood cells (WBCs) counts, reticulocyte counts, level of complement, bone marrow features, and so on. A multiple correspondence analysis (MCA) of the association between variables corresponds to a cross-tabulation of categorical variables and a multidimensional scaling technique. The results of MCA were graphically presented in a 2-dimensional Euclidean space. This study was approved by Renji hospital ethics committee.

Statistical analysis. A descriptive statistical analysis was developed in Excel (Microsoft Corp). Normally and non-normally distributed continuous variables were respectively summarized as the median and interquartile range (IQR). Discrete variables were summarized as percentages. In order to identify predictors for response, we performed a univariate analysis such as Chi-square or nonparametric test of baseline variables between responder and non-responder of eltrombopag in patients with CTD-ITP. To visualize homogeneous clusters of patients with distinct response to eltrombopag, we included all baseline variables (Table 3) showing p-values $<0.1$ in univariate analysis by MCA as previously described ${ }^{9,10}$. We stated that all methods were carried out in accordance with relevant guidelines and regulations.

\section{Results}

Patient characteristics. A total of 15 female patients with refractory CTD-ITP were enrolled in this study. There are 9 SLE patients, 3 SS patients, 3 patients diagnosed with UCTD. Only one patient was APS (tested positive for aPL and $\beta 2$-GPI). Their median age at the time of inclusion was 40.6 years (IQR, 16-63 years). The median protopathy duration was 6.87 years (IQR, $0-31$ years), the severe thrombocytopenia was 4.8 years (IQR, 0-16 years), and the median disease duration before the onset of severe thrombocytopenia was 2.07 years. In 13 patients, severe thrombocytopenia was the presenting manifestation of protopathy. The lowest platelet counts were less than $15 \times 10^{9} / \mathrm{L}$ in all patients. All patients were refractory to a high dose of corticosteroids (at least $1 \mathrm{mg} / \mathrm{kg}$ day) and prior immunosuppressive treatment with thrombocytopenia, including cyclosporine $\mathrm{A}$ (86.7\%, 13/15), IVIG (53.3\%, 8/15), TPO (33.3\%, 5/13), rituximab (13.3\%, 2/15) and other therapy (e.g., azathioprine, cyclophosphamide, mycophenolate mofetil, hydroxychloroquine). Among 15 patients with CTD-ITP, only one patient was suffering from hepatitis B cirrhosis, splenomegaly, and hyperthyroidism; 1 patient had ovarian cancer. Among 9 patients with SLE, the disease activity of one patient was severe, while most of the patients were stable or mild as measured by systemic lupus erythematosus disease activity index (SLEDAI) score.

Bone marrow aspiration was performed in 11 patients, where 5 patients showed a typical ITP. Patient characteristics, prior immunosuppressive treatments, and bone marrow feature are summarized in Table 1 .

Efficacy of eltrombopag on refractory CTD-ITP. The median platelet count at initiation of eltrombopag was $11.53 \times 10^{9} / \mathrm{L}\left(\mathrm{IQR}, 1-30 \times 10^{9}\right) ; 12(80 \%)$ patients had a baseline platelet count $15 \times 10^{9} / \mathrm{L}$ or less. All subjects received eltrombopag at a dose of $25 \mathrm{mg} /$ day, except one patient who received $50 \mathrm{mg} /$ day. Nearly all the patients $(93.33 \%, 14 / 15)$ completed 4 weeks treatment with eltrombopag; one patient discontinued the treatment of eltrombopag for complete remission, while 3 patients discontinued as lacking efficacy after 4 weeks treatment. The baseline platelet counts before treatment and platelet counts change curves at each time point are shown in Fig. 1A.

The median duration of therapy was 21.2 weeks (2-104 weeks), and the median remission time was 3.42 weeks (1-12 weeks) (Fig. 1B). Most of the patients $(80 \%, 12 / 15)$ reposed well to eltrombopag. As shown in Fig. 1C, the CR and overall response rate was $26.67 \%$ and $66.67 \% 4$ weeks later, respectively. However, the CR and overall response rate decreased with time; the CR rate was 13.33\%, and the overall response rate was $40 \% 6$ months later. The severe adverse events were seldom, except in one patient who stopped taking eltrombopag 4 weeks 


\begin{tabular}{|c|c|c|c|c|c|c|c|c|c|c|c|c|c|}
\hline Patient & Age, years & Sex & Protopathy & $\begin{array}{l}\begin{array}{l}\text { Diagnosis time for } \\
\text { protopathy }\end{array} \\
\end{array}$ & $\begin{array}{l}\text { Diagnosis time for } \\
\text { thrombocytopenia }\end{array}$ & \begin{tabular}{|l|}
$\begin{array}{l}\text { Lowest platelet } \\
\text { counts }\left(\times 10^{9} / \mathrm{L}\right)\end{array}$ \\
\end{tabular} & Previous treatments & Complications & Acompanying diseases & APS & Reticulocytes ratio $(\%)$ & \begin{tabular}{|l|}
$\begin{array}{l}\text { Bone marrow } \\
\text { puncture }\end{array}$ \\
\end{tabular} & SLEDAI \\
\hline 1 & 54 & F & SLE & 1988 & 2014 & 2 & $\begin{array}{l}\text { Pred,CysA, CTX, } \\
\text { IVIG, vincristine, } \\
\text { transfused platelets }\end{array}$ & No & Hypertension Diabetes & Yes & 2.14 & NA & 3 \\
\hline 2 & 54 & F & SLE & 2005 & 2005 & 12 & Pred, CysA & No & $\begin{array}{l}\text { HBC,Spleno-megaly, } \\
\text { Hyperthyroid-ism }\end{array}$ & No & NA & NA & \\
\hline 3 & 31 & F & SLE & 2005 & 2005 & 5 & Pred, CysA, AZA & No & No & No & NA & NA & \\
\hline 4 & 47 & F & UCTD & 2015 & 2015 & 9 & Pred, CysA & No & No & No & 3.97 & NA & 1 \\
\hline 5 & 42 & F & ss & 2016 & 2016 & 7 & $\begin{array}{l}\text { Pred, HCQ, CysA, } \\
\text { IVIG, TPO }\end{array}$ & No & No & No & 2.74 & AA & \\
\hline 6 & 37 & F & SLE & 2013 & 2018 & 1 & $\begin{array}{l}\text { Pred, HCQ, CysA, } \\
\text { MMF, IVIG, } \\
\text { splenectomy }\end{array}$ & $\begin{array}{l}\text { Autoimmune hemolytic } \\
\text { anemia }\end{array}$ & No & No & 2.31 & Normal & 1 \\
\hline 7 & 22 & F & SLE & 2018 & 2018 & 9 & Pred, CysA, TPO & No & No & No & 1.23 & ITP & 5 \\
\hline 8 & 16 & M & SLE & 2017 & 2017 & 3 & Pred, CysA, IVIG & No & No & No & \begin{tabular}{|l|l|}
2.47 & \\
\end{tabular} & ITP & 3 \\
\hline 9 & 40 & F & SLE & 2018 & 2018 & 1 & $\begin{array}{l}\text { Pred, HCQ, CysA, } \\
\text { IVIG, RTX }\end{array}$ & PAH & No & No & 5.24 & ITP & 5 \\
\hline 10 & 53 & F & ss & 2003 & 2003 & 4 & $\begin{array}{l}\text { Pred, } \mathrm{HCQ} \text {, trans- } \\
\text { fused platelets }\end{array}$ & No & No & No & 3.39 & $\begin{array}{l}\text { Megakaryocyto- } \\
\text { pen-ia }\end{array}$ & \\
\hline 11 & 63 & M & UCTD & 2019 & 2019 & 3 & $\begin{array}{l}\text { Pred, CysA, IVIG, } \\
\text { TPO }\end{array}$ & No & No & No & 1.73 & Normal & \\
\hline 12 & 54 & F & ss & 2018 & 2018 & 2 & $\begin{array}{l}\text { Pred, CysA, IVIG, } \\
\text { TPO }\end{array}$ & No & Ovarian cancer & No & 0.55 & $\begin{array}{l}\begin{array}{l}\text { Megakar-yocyte } \\
\text { deficiency }\end{array} \\
\end{array}$ & \\
\hline 13 & 27 & F & SLE & 2014 & 2014 & 10 & $\begin{array}{l}\text { Pred, CysA, IVIG, } \\
\text { CTX, RTX, plasma } \\
\text { exchange }\end{array}$ & No & No & No & 1.76 & MAS & 16 \\
\hline 14 & 22 & $\mathrm{M}$ & UCTD & 2015 & 2015 & 10 & Pred & No & No & No & NA & ITP & \\
\hline 15 & 47 & F & SLE & 2018 & 2018 & 12 & Pred, CysA & No & No & No & NA & ITP & 1 \\
\hline
\end{tabular}

Table 1. Patient characteristics. F female, $M$ male, SLE systemic lupus erythematosus, $S S$ sjogren's syndrome, UCTD undifferentiated connective tissue disease, Pred prednisolone, CysA cyclosporin A, AZA azathioprine, HCQ hydroxychloroquine, IVIG intravenous immunoglobulin, MMF mycophenolate mofetil, TPO thrombopoietin, RTX rituximab, CTX cyclophosphamide, $P A H$ pulmonary hypertension, APS anticardiolipin antibody syndrome, ITP idiopathic thrombocytopenia, $M A S$ hemophagocytic syndrome, $H B C$ hepatitis B cirrhosis, SLEDAI systemic lupus erythematosus disease activity index, NA non acceptance.

later for severe oral ulcers. The treatment regimen, response, TTR, duration of eltrombopag, and adverse events are shown in Table 2.

Identification of predictive factors for eltrombopag. To investigate the predictive factors for eltrombopag in refractory CTD-ITP, we first compared baseline variables between responder and non-responder of eltrombopag in patients with CTD-ITP by univariate analysis. Some potentially baseline variables (defined as $p$-values $<0.1)$ for the efficacy of eltrombopag among patients with CTD-ITP were shown in Table 3 , including protopathy $(\mathrm{p}=0.071)$, WBCs counts $(p=0.004)$, levels of hemoglobin $(p=0.002)$, and characteristics of bone marrow findings $(p=0.01)$. To graphically represent the association of categorical variables in a 2-dimensional Euclidean space, we then performed a MCA based on the baseline clinical manifestations and laboratory findings. With a Cronbach's alpha of 0.905 and variance of $77.7 \%$ for the modeling, the dimension 1 (the horizontal axis) seemed to separate two distinct clusters with favorable or unfavorable factors for the use of eltrombopag in patients with refractory CTD-ITP. As shown in Fig. 2, medium to severe anemia, leukopenia, bone marrow aspiration showing aplastic anemia (AA), an absence of megakaryocytes or macrophage activation syndrome (MAS), and a protopathy with SS have been associated with the poor response to eltrombopag in patients with refractory CTD-ITP. While, patients with normal WBCs counts, no or slight anemia, and relative normal bone marrow aspiration have been associated with a good response to eltrombopag.

\section{Discussion}

Eltrombopag is a thrombopoietin-receptor agonist (TPO-RA) that mimics the action of endogenous TPO on megakaryocytes and megakaryocyte precursors, promoting their growth and differentiation, thus, increasing platelet production ${ }^{11}$. In 2018, guidelines for ITP recommended TPO-RAs for patients who did not respond well to glucocorticoids or rituximab, or those with splenectomy ${ }^{12}$. In this study, we performed a real-world investigation of eltrombopag treatment for patients with CTD-ITP. Our results demonstrated that eltrombopag might be an effective therapy for patients with ITP secondary to autoimmune diseases who did not respond well to standard ITP treatment.

In this study, $80 \%$ of patients responded well to eltrombopag. Most of our patients received a dose of eltrombopag of $25 \mathrm{mg} /$ day, which has been recommended for patients of East Asian descent. Eltrombopag was well tolerated, except for severe oral ulcers, which were observed in one patient. The median time taken for initial response to eltrombopag was 3.42 weeks, and peak response rate occurred after a one-month treatment. Many positive results in terms of effectiveness and maintained platelet response rate of eltrombopag have been reported in the treatment of chronic ITP ${ }^{13,14}$. Interestingly, we found that the response rate gradually declined until reaching the plateau stage. It might be related to the small dose of eltrombopag administrated on the CTD-ITP patients, and also the clinical severity of the primary disease for CTD-ITP. Indeed, several clinical trials observed the similar plateau phenomenon in more than half of robust responders of eltrombopag in refractory severe aplastic 

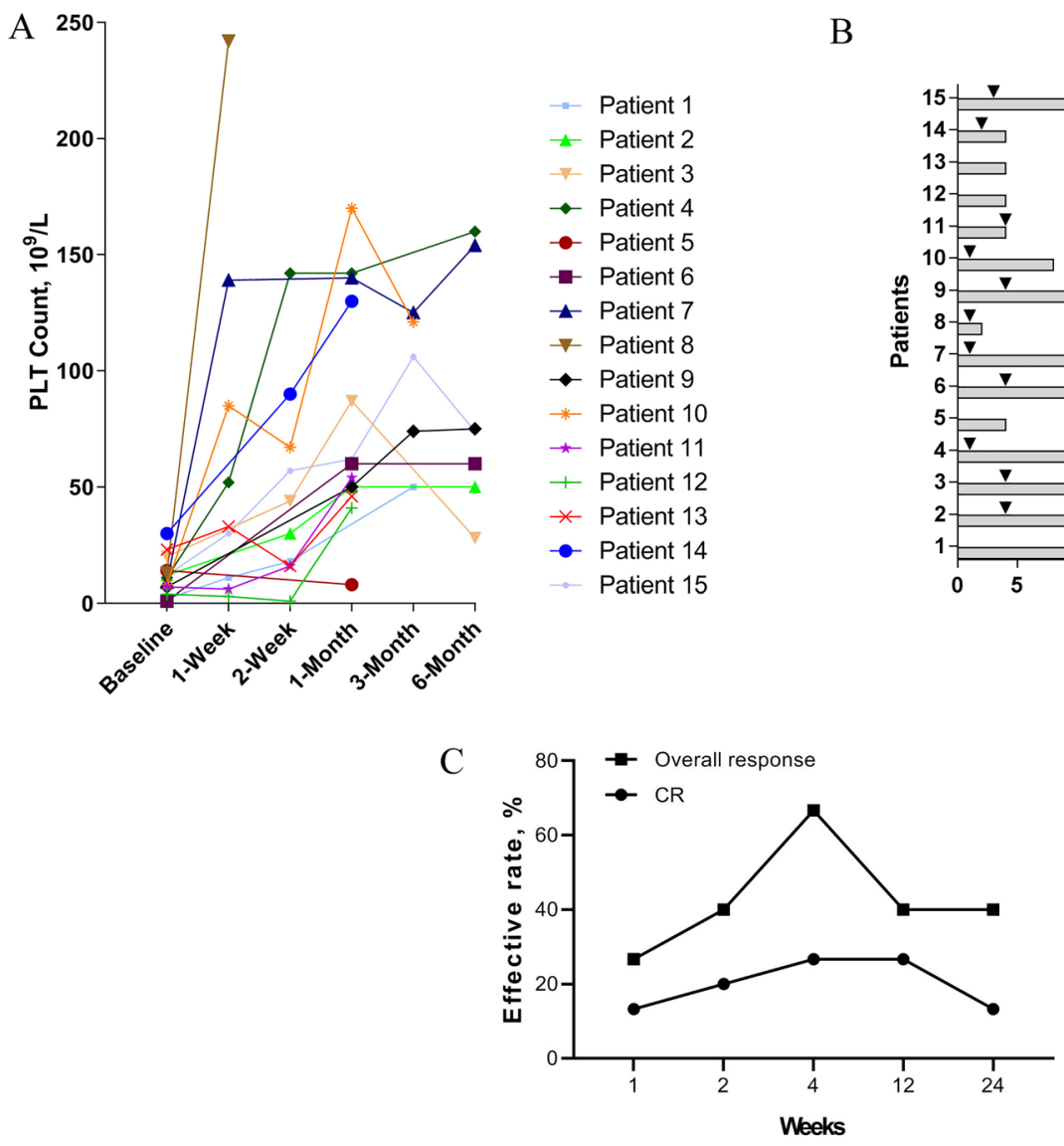

Figure 1. (A) The baseline platelet counts before treatment and platelet counts change curves at each time point during treatment with eltrombopag. (B) Total duration of treatment and time taken for response to therapy until August 2019. (C) The complete remission (CR) rate and overall response rate at each point during treatment with eltrombopag.

anemia ${ }^{15}$ or patients with chronic immune thrombocytopenia ${ }^{16}$. Furthermore, the effect of eltrombopag on cell proliferation rates may also have a plateau phenomenon ${ }^{17}$.

A number of studies have indicated that TPO-RAs is associated with thrombotic risk when treating patients with chronic liver disease and those having antiphospholipid antibodies (aPL) ${ }^{18-22}$. In our study, one patient had hepatitis B cirrhosis, and another one was aPL and $\beta 2$-GPI positive; yet, no thromboembolic events were observed after 26 weeks and 16 weeks treatments, respectively.

Many ITP real-world studies evaluated clinical and laboratory variables associated with response to eltrombopag and the relative factors, including age, anemia, bone marrow features, and so on ${ }^{11}$. In our study, we found that anemia, decreased WBCs counts, bone marrow aspiration showing aplastic anemia, an absence of megakaryocytes or macrophage activation syndrome (MAS) were predictors of worse outcome. Bone marrow characteristics such as megakaryocytopenia, bone marrow hypocellularity, and dyserythropoiesis were predictors of worse outcome ${ }^{23}$. Eltrombopag is effective in ITP, aplastic anemia (AA), and myelodysplastic syndromes (MDS), which is probably due to a sort of spillover specificity on other growth factor receptors, as well as to the action at the stem-cell level ${ }^{11}$. On the whole, although responses are observed in MDS and AA, eltrombopag is more effective in classic ITP, confirming the importance of megakaryocytic reservoir ${ }^{23,24}$. Indeed, marrow megakaryocyte count could be a response predictor of severe thrombocytopenia in patients with SLE and SS ${ }^{25,26}$. However, more prospective studies are warranted to address whether SS-ITP patients have a poor response to eltrombopag than other CTD-ITP patients.

This study has a few limitations. First, the sample size was small. Second, because this is a retrospective study, possible recall and selection errors cannot be excluded.

\section{Conclusions}

Eltrombopag is effective and well-tolerated in CTD-associated thrombocytopenia. Some factors should be considered in the use of eltrombopag, including the disease of protopathy, blood test, and bone marrow aspiration. Additional large studies would be needed to confirm the results. 


\begin{tabular}{|c|c|c|c|c|c|}
\hline Patient & Treatment regimen & Type of response (PR/CR/negative) & Time to response (weeks) & Duration of Eltrombopag, (weeks) & Adverse events \\
\hline 1 & $\begin{array}{l}\text { Pred } 60 \mathrm{mg} / \text { day, CysA75mg/bid, Eltrom- } \\
\text { bopag } 25 \mathrm{mg} / \text { day }\end{array}$ & PR & 12 & 16 & None \\
\hline 2 & Pred $30 \mathrm{mg} /$ day, Eltrombopag $25 \mathrm{mg} /$ day & PR & 2 & 26 & None \\
\hline 3 & Pred $15 \mathrm{mg} /$ day, Eltrombopag $25 \mathrm{mg} /$ day & PR & 2 & 26 & None \\
\hline 4 & Pred $40 \mathrm{mg} /$ day, Eltrombopag $25 \mathrm{mg} /$ day & CR & 1 & 36 & None \\
\hline 5 & $\begin{array}{l}\text { Pred } 50 \mathrm{mg} / \text { day, CysA } 50 \mathrm{mg} / \text { tid, Eltrom- } \\
\text { bopag } 25 \mathrm{mg} / \text { bid }\end{array}$ & Negative & - & 4 & None \\
\hline 6 & $\begin{array}{l}\text { Pred } 60 \mathrm{mg} / \text { day, CysA } 75 \mathrm{mg} / \mathrm{bid} \text {, } \\
\text { Eltrombopag } 25 \mathrm{mg} / \text { day }\end{array}$ & PR & 4 & 104 & None \\
\hline 7 & Pred $60 \mathrm{mg} /$ day, Eltrombopag $25 \mathrm{mg} /$ day & CR & 1 & 28 & None \\
\hline 8 & $\begin{array}{l}\text { Pred } 60 \mathrm{mg} / \text { day, CysA } 100 \mathrm{mg} / \mathrm{bid} \text {, } \\
\text { Eltrombopag } 25 \mathrm{mg} / \text { day }\end{array}$ & $\mathrm{CR}$ & 3 days & 2 & None \\
\hline 9 & $\begin{array}{l}\text { Pred } 15 \mathrm{mg} / \text { day, Eltrombopag } 25 \mathrm{mg} / \text { day, } \\
\text { tacrolimus } 1 \mathrm{mg} / \text { day }\end{array}$ & PR & 4 & 26 & None \\
\hline 10 & $\begin{array}{l}\text { Pred } 40 \mathrm{mg} / \text { day, CysA } 75 \mathrm{mg} / \mathrm{bid} \text {, } \\
\text { Eltrombopag } 25 \mathrm{mg} / \text { day }\end{array}$ & PR & 2 & 8 & None \\
\hline 11 & $\begin{array}{l}\text { Pred } 40 \mathrm{mg} / \text { day, CysA } 75 \mathrm{mg} / \mathrm{bid}, \\
\text { Eltrombopag } 25 \mathrm{mg} / \text { day }\end{array}$ & PR & 2 & 4 & Oral ulcer \\
\hline 12 & Pred80mg/day, Eltrombopag $25 \mathrm{mg} /$ day & Negative & - & 4 & None \\
\hline 13 & $\begin{array}{l}\text { Pred } 40 \mathrm{mg} / \text { day, Tacrolimus } 1 \mathrm{mg} / \text { day, } \\
\text { Eltrombopag } 25 \mathrm{mg} / \text { day, RTX } 100 \mathrm{mg} / \\
\text { week }\end{array}$ & Negative & - & 4 & None \\
\hline 14 & Pred $5 \mathrm{mg} /$ day, Eltrombopag $25 \mathrm{mg} /$ day & $\mathrm{CR}$ & 2 & 4 & None \\
\hline 15 & $\begin{array}{l}\text { Pred } 40 \mathrm{mg} / \text { day, CysA } 75 \mathrm{mg} / \mathrm{bid}, \\
\text { Eltrombopag } 25 \mathrm{mg} / \text { day }\end{array}$ & $\mathrm{CR}$ & 3 & 26 & None \\
\hline
\end{tabular}

Table 2. Treatment regimen, response, time to response, total duration of treatment and adverse events of the drug were analysed. Pred prednisolone, CysA cyclosporin A, RTX rituximab, $P R$ partial response, CR complete remission. 


\begin{tabular}{|c|c|c|c|}
\hline \multirow[b]{2}{*}{ Baseline variables } & \multicolumn{2}{|c|}{ Efficacy of eltrombopag } & \multirow[b]{2}{*}{$p^{*}$} \\
\hline & Responder, $\mathrm{n}=12$ & Non-responder, $n=3$ & \\
\hline Age, years & $40.5 \pm 15.1$ & $41 \pm 13.5$ & 0.945 \\
\hline$\geq 50$ old-year & 4 & 1 & 0.758 \\
\hline Female: Male & $9: 3$ & $3: 0$ & 0.484 \\
\hline \multicolumn{3}{|l|}{ Protopathy } & 0.071 \\
\hline Systemic lupus erythematosus & 8 & 1 & 0.341 \\
\hline Sjögren's syndrome & 1 & 2 & 0.081 \\
\hline UCTD & 3 & 0 & 0.484 \\
\hline Duration of platelet reduction $>1$ year & 6 & 2 & 0.554 \\
\hline Splenomegaly & 3 & 0 & 0.453 \\
\hline \multicolumn{4}{|l|}{ Prior therapy } \\
\hline High dose of corticosteroids ${ }^{\#}$ & 12 & 3 & 1.000 \\
\hline Intravenous immunoglobulin & 5 & 2 & 0.446 \\
\hline Use of TPO & 3 & 2 & 0.242 \\
\hline Rituximab & 1 & 1 & 0.371 \\
\hline CysA & 9 & 3 & 0.484 \\
\hline HCQ & 4 & 1 & 0.758 \\
\hline CTX & 1 & 1 & 0.371 \\
\hline \multicolumn{4}{|l|}{ Laboratory examination } \\
\hline WBCs counts, $10^{9} / \mathrm{L}$ & $8.0 \pm 3.9$ & $2.1 \pm 0.7$ & 0.004 \\
\hline Leukopenia $\left(<4.0 \times 10^{9} / \mathrm{L}\right)$ & 2 & 3 & 0.022 \\
\hline Hemoglobin, mg/dL & $131.7 \pm 25.7$ & $70.3 \pm 13.2$ & 0.009 \\
\hline \multicolumn{3}{|l|}{ Anemia } & 0.002 \\
\hline Normal ( $\geq 120 \mathrm{mg} / \mathrm{dL})$ & 10 & 0 & \\
\hline Slight degree ( $\geq 90 \mathrm{mg} / \mathrm{dL})$ & 2 & 0 & \\
\hline Medium degree $(60-90 \mathrm{mg} / \mathrm{dL})$ & 0 & 2 & \\
\hline Severe degree $(<60 \mathrm{mg} / \mathrm{dL})$ & 0 & 1 & \\
\hline Elevated reticulocyte counts & 7 & 2 & 0.491 \\
\hline Low level of complement & 6 & 2 & 0.615 \\
\hline \multicolumn{3}{|l|}{ Characteristics of bone marrow findings } & 0.01 \\
\hline Normal & 6 & 0 & \\
\hline ITP & 5 & 0 & \\
\hline Aplastic anemia & 0 & 1 & \\
\hline Megakaryocytopenia & 1 & 0 & \\
\hline Lack of megakaryocytes & 0 & 1 & \\
\hline Macrophage activation syndrome & 0 & 1 & \\
\hline
\end{tabular}

Table 3. Comparison of baseline variables between responder and non-responder of eltrombopag in patients with connective tissue disease-associated immune thrombocytopenia (CTD-ITP). Continuous variables were presented as mean \pm (standard deviation). Cys A cyclosporine A, CTX cyclophosphamide, HCQ hydroxychloroquine, ITP idiopathic thrombocytopenic purpura, UCTD undifferentiated connective tissue disease, WBCs white blood cells, TPO thrombopoietin. ${ }^{\star} \mathrm{p}$ was shown with exact significance on one-sided or asymptotic significance on two-sided. "High dose of corticosteroids were defined as at least $1 \mathrm{mg} / \mathrm{kg}$ day; responder, complete remission plus partial response. 


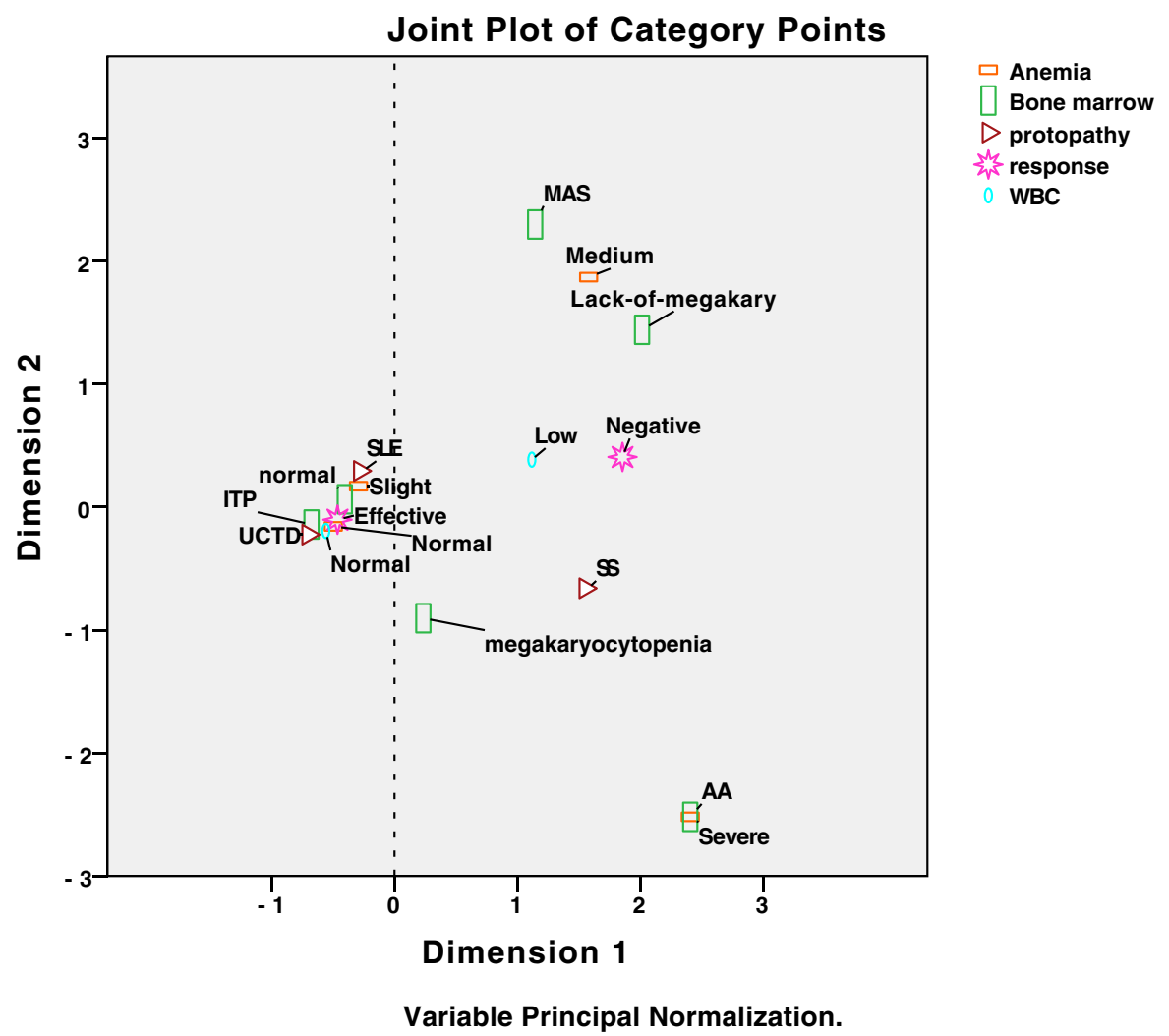

Figure 2. The multiple correspondence analysis (MCA) data for predictive factors for eltrombopag. Variables used in this analysis were anemia, white blood cells (WBCs) counts, bone marrow features, protopathy. For clarity, only the most discriminant variables are represented. AA aplastic anemia, MAS macrophage activation syndrome, SLE systemic lupus erythematosus, SS Sjogren's syndrome, UCTD undifferentiated connective tissue disease, ITP idiopathic thrombocytopenic purpura.

Received: 5 October 2020; Accepted: 8 February 2021

Published online: 09 March 2021

\section{References}

1. Arnal, C. et al. Treatment of severe immune thrombocytopenia associated with systemic lupus erythematosus: 59 cases. J Rheumatol 29(1), 75-83 (2002).

2. Bussel, J. B. et al. Effect of eltrombopag on platelet counts and bleeding during treatment of chronic idiopathic thrombocytopenic purpura: A randomised, double-blind, placebo-controlled trial. Lancet 373(9664), 641-648. https://doi.org/10.1016/S0140 -6736(09)60402-5 (2009).

3. Lusa, A. \& Carlson, A. Safety and efficacy of thrombopoeitin mimetics for refractory immune thrombocytopenia purpura in patients with systemic lupus erythematosus or antiphospholipid syndrome: A case series. Lupus 27(10), 1723-1728. https://doi. org/10.1177/0961203318770023 (2018).

4. Magnano, L., Enriquez, H., Esteve, J., Cervera, R. \& Espinosa, G. Effectiveness of thrombopoietin-receptor agonists in the treatment of refractory immune thrombocytopenia associated to systemic lupus erythematosus. J. Rheumatol. 41(9), 1895-1896. https ://doi.org/10.3899/jrheum.140080 (2014).

5. Shobha, V., Sanil, S. \& Roongta, R. Eltrombopag: Efficacy and safety in steroid refractory lupus-associated immune thrombocytopenia. J. Clin. Rheumatol. 26(7), 274-278. https://doi.org/10.1097/RHU.0000000000001083 (2020).

6. Petri, M. et al. Derivation and validation of the Systemic Lupus International Collaborating Clinics classification criteria for systemic lupus erythematosus. Arthritis Rheum. 64(8), 2677-2686. https://doi.org/10.1002/art.34473 (2012).

7. Shiboski CH, Shiboski SC, Seror R, Criswell LA, Labetoulle M, Lietman TM, Rasmussen A, Scofield H, Vitali C, Bowman SJ, Mariette X, International Sjogren's Syndrome Criteria Working G. 2016 American College of Rheumatology/European League Against Rheumatism Classification criteria for primary Sjogren's syndrome: A consensus and data-driven methodology involving three international patient cohorts. Arthritis Rheumatol. 69(1), 35-45. https://doi.org/10.1002/art.39859 (2017).

8. Ghanima, W., Cooper, N., Rodeghiero, F., Godeau, B. \& Bussel, J. B. Thrombopoietin receptor agonists: Ten years later. Haematologica 104(6), 1112-1123. https://doi.org/10.3324/haematol.2018.212845 (2019).

9. Dion, J. et al. Relapsing polychondritis can be characterized by three different clinical phenotypes: Analysis of a recent series of 142 patients. Arthritis Rheumatol. 68(12), 2992-3001. https://doi.org/10.1002/art.39790 (2016).

10. Sourial, N. et al. Correspondence analysis is a useful tool to uncover the relationships among categorical variables. J. Clin. Epidemiol. 63(6), 638-646. https://doi.org/10.1016/j.jclinepi.2009.08.008 (2010).

11. Fattizzo, B., Levati, G., Cassin, R. \& Barcellini, W. Eltrombopag in immune thrombocytopenia, aplastic anemia, and myelodysplastic syndrome: From megakaryopoiesis to immunomodulation. Drugs 79(12), 1305-1319. https://doi.org/10.1007/s40265-019-01159 -0 (2019).

12. Matzdorff, A. et al. Immune thrombocytopenia: Current diagnostics and therapy: recommendations of a joint working group of DGHO, OGHO, SGH, GPOH, and DGTI. Oncol. Res. Treat 41(Suppl 5), 1-30. https://doi.org/10.1159/000492187 (2018). 
13. Gonzalez-Porras, J. R. \& Bastida, J. M. Eltrombopag in immune thrombocytopenia: efficacy review and update on drug safety. Ther. Adv. Drug Saf. 9(6), 263-285. https://doi.org/10.1177/2042098618769587 (2018).

14. Giordano, P. et al. Use of eltrombopag in children with chronic immune thrombocytopenia (ITP): A real life retrospective multicenter experience of the italian association of pediatric hematology and oncology (AIEOP). Front. Med. (Lausanne) 7, 66. https ://doi.org/10.3389/fmed.2020.00066 (2020).

15. Winkler, T. et al. Treatment optimization and genomic outcomes in refractory severe aplastic anemia treated with eltrombopag. Blood 133(24), 2575-2585. https://doi.org/10.1182/blood.2019000478 (2019).

16. Liu, X. et al. Efficacy and safety of eltrombopag in Chinese patients with chronic immune thrombocytopenia: stage 2 results from a multicenter phase III study. Platelets 1, 1-7. https://doi.org/10.1080/09537104.2020.1847267 (2020).

17. Erickson-Miller, C. L. et al. Preclinical activity of eltrombopag (SB-497115), an oral, nonpeptide thrombopoietin receptor agonist. Stem Cells 27(2), 424-430. https://doi.org/10.1634/stemcells.2008-0366 (2009).

18. LaMoreaux, B., Barbar-Smiley, F., Ardoin, S. \& Madhoun, H. Two cases of thrombosis in patients with antiphospholipid antibodies during treatment of immune thrombocytopenia with romiplostim, a thrombopoietin receptor agonist. Semin. Arthritis. Rheum. 45(4), e10-12. https://doi.org/10.1016/j.semarthrit.2015.07.008 (2016).

19. Borrell, H., Nolla, J.M., Narvaez, J. Letter to the editor. Commentary to the article: LaMoreaux B, Barbar-smiley F, Ardoin S, Madhoun $\mathrm{H}$. Two cases of thrombosis in patients with antiphospholipid antibodies during treatment of immune thrombocytopenia with romiplostin, a thrombopoietin receptor agonist. Semin Arthritis Rheum 2015 Jul 29.pii: S0049-0172(15)00196-1. https:// doi.org/10.1016/j.semarthrit.2015.07-008. [Epub ahead of print]. Semin. Arthritis. Rheum. 45(5):e16. https://doi.org/10.1016/j. semarthrit.2015.10.007 (2016).

20. Boulon, C., Vircoulon, M. \& Constans, J. Eltrombopag in systemic lupus erythematosus with antiphospholipid syndrome: Thrombotic events. Lupus 25(3), 331. https://doi.org/10.1177/0961203315608257 (2016).

21. Gonzalez-Lopez, T. J. et al. Use of eltrombopag for secondary immune thrombocytopenia in clinical practice. Br. J. Haematol. 178(6), 959-970. https://doi.org/10.1111/bjh.14788 (2017).

22. Afdhal NH, Giannini EG, Tayyab G, Mohsin A, Lee JW, Andriulli A, Jeffers L, McHutchison J, Chen PJ, Han KH, Campbell F, Hyde D, Brainsky A, Theodore D, Group ES. Eltrombopag before procedures in patients with cirrhosis and thrombocytopenia. $N$. Engl. J. Med. 367(8), 716-724. https://doi.org/10.1056/NEJMoa1110709 (2012).

23. Fattizzo, B. et al. Bone marrow characteristics predict outcome in a multicenter cohort of primary immune thrombocytopenia patients treated with thrombopoietin analogs. Haematologica 104(10), e470-e473. https://doi.org/10.3324/haematol.2019.21680 4 (2019).

24. Stasi, R. Eltrombopag: the discovery of a second generation thrombopoietin-receptor agonist. Expert Opin. Drug Discov. 4(1), 85-93. https://doi.org/10.1517/17460440802642484 (2009).

25. Xue, Y., Xu, D., Li, M. T. \& Zeng, X. F. Marrow megakaryocyte count as a response predictor of severe thrombocytopenia in patients with primary Sjogren syndrome. Zhonghua Nei Ke Za Zhi 58(4), 282-287. https://doi.org/10.3760/cma.j.issn.0578-1426.2019.04.009 (2019).

26. Zhao, L., Xu, D., Qiao, L. \& Zhang, X. Bone marrow megakaryocytes may predict therapeutic response of severe thrombocytopenia in patients with systemic lupus erythematosus. J. Rheumatol. 43(6), 1038-1044. https://doi.org/10.3899/jrheum.150829 (2016).

\title{
Author contributions
}

S.C. conceptualized and designed this study. J.W. contributed to data acquisition, analysis, and interpretation. J.W., M.D., Q.F. and S.C. compiled the manuscript. All authors approved the manuscript. S.C. and J.W. is the guarantor of this work and, as such, had full access to all the data in the study and assumes responsibility for the integrity of the data and the accuracy of the data analysis.

\section{Funding}

This work was supported by the National Natural Science Foundation of China (No. 81801593, No.81771752) and the National Key Research and Development Program of China (2017YFC0909002).

\section{Competing interests}

The authors declare no competing interests.

\section{Additional information}

Correspondence and requests for materials should be addressed to S.C.

Reprints and permissions information is available at www.nature.com/reprints.

Publisher's note Springer Nature remains neutral with regard to jurisdictional claims in published maps and institutional affiliations.

\begin{abstract}
Open Access This article is licensed under a Creative Commons Attribution 4.0 International License, which permits use, sharing, adaptation, distribution and reproduction in any medium or format, as long as you give appropriate credit to the original author(s) and the source, provide a link to the Creative Commons licence, and indicate if changes were made. The images or other third party material in this article are included in the article's Creative Commons licence, unless indicated otherwise in a credit line to the material. If material is not included in the article's Creative Commons licence and your intended use is not permitted by statutory regulation or exceeds the permitted use, you will need to obtain permission directly from the copyright holder. To view a copy of this licence, visit http://creativecommons.org/licenses/by/4.0/.
\end{abstract}

(c) The Author(s) 2021 